\title{
Assessment Practices in Mathematics Courses: Towards Dialectical Positioning
}

\author{
Bed Raj Acharya \\ Central Department of Education \\ Department of Mathematics Education, T.U. \\ E-mail: acharyabedraj@yahoo.com
}

\begin{abstract}
This article aims to explore the perception and practices of mathematics teachers on assessment system in mathematics courses. I adopted interpretive research approach. Three schools each from Gorkha, Nuwakot and Kaski district were selected for study. Six students, three teachers, three head teachers, and three resource persons were the interviewees of the study. I observed classrooms and conducted FGDs for collecting textual information. The data was generated from these different sources of each school have been verified and critically analyzed through triangulation and generate themes. It was found that, existing assessment practices were formative assessments such as project work, class work, and homework, attendance, unit test, remedial support, extracurricular activities, field visit, group discussion, weekly tests and use of summative evaluation as a formative assessment tool.
\end{abstract}

Key words: Dialectical, Positioning, Assessment, Practices

\section{The Context}

Assessment of students learning is one of the components of a total teaching and learning process. Continuous assessment system can foster learning attitude as well as better performance. Assessment is a general term that includes full range of procedures used to gain information about learning and formation of values of judgment concerning progress of students in relation to set standards. Assessment judges the students' learning purpose when they know and what they are supposed to learn. It provides opportunity to receive regular feedback and know what is expected in order to meet each standard. Mainly evaluation is categorized into diagnostic, formative and summative - means evaluation to learning, evaluation for learning and evaluation of learning respectively .Tu (2009) highlighted the assessment practices of mathematics in schools of China. According to this the main assessment of Chinese mathematics education are school work-based assessment, selection-aimed promotion assessment and competition-based assistant assessment. Work-based assessment include: Routine assessment, period assessment and concluding assessment. Selection-aimed promotion assessment include: Senior high school entrance examination, college entrance examination. Thus, there are several forms of assessment practices in mathematics education. 
Teachers use observations and alternative assessments more than traditional methods and these measures are more valid measures of student achievement. They argue that more experienced teachers use alternative methods of assessment than less experienced teachers (as cited in Ghaicha, 2016). Moreover, Vandeyarand Killen (2007) argue that educators' conceptions of assessment drive their practices. In Nepal, National Curriculum Framework for School Education in Nepal (2007) stresses on formative and summative assessment system for assessing the learning performance of the students.

Student assessment must be done by both internal and external assessment using formal as well as informal testing devices at all levels and grades. In line of this framework, there are several strategies of assessment such as, class work, project work, community work, unit test, achievement test, trimester, observation, formative and innovative work, and so on which are, in one or other ways, in practice in schools of Nepal. Summative assessment is used for certification of students' achievement and grade promotion. Moreover, there are practices of continuous assessment system.

The ongoing assessment practices are useful to measure the different skills, intelligence and behavior of the students from multiple learning abilities (Altan, 2002). Airasion (1999) has discussed the multiple problems that appear in the classroom for promoting effective assessment particularly in the process of applying ongoing assessment. How do teachers assess the students' performance in mathematics courses at school level? Why do the teachers appear less encouraged to apply formative assessment in mathematics education? In this context, the key purpose of this paper is to explore the perception and practices of mathematics teachers on formative assessment.

\section{Conceptual Framework}

The conceptual framework has been developed based on the literature studies. This provides a map of the study for addressing research objectives.

The conceptual framework shows the key focus areas of the inquiry. It is the researcher's own position on the problem and gives direction to the study. It is an adaptation of a model used in a previous study, with modifications to suit the investigation. A conceptual framework is an analytical tool incorporate with several variations and contexts. It is used to make conceptual distinctions and organize ideas. Strong conceptual frameworks capture something real and do this in a way that is easy to remember and apply. A conceptual framework explains, mostly graphically, the main things to be studied - the key factors, constructs or variables - and the presumed relationships among them. List all the variables and concepts and brainstorm to visualize how they relate to each other. On the left side there mention issues in the research. On right side there mention methodology which should be applied by researcher for research purpose. When if there will well management of assessment practice, and method, possible outcome will be good practice of assessment system which are also addressed on right side of the above figure. As National curriculum framework (NCF 2007) address tools of assessment on school level on basis of those assessments' tools researchers observed as intended assessment practice by NCF in real classroom those assessment practices are applied or not. 


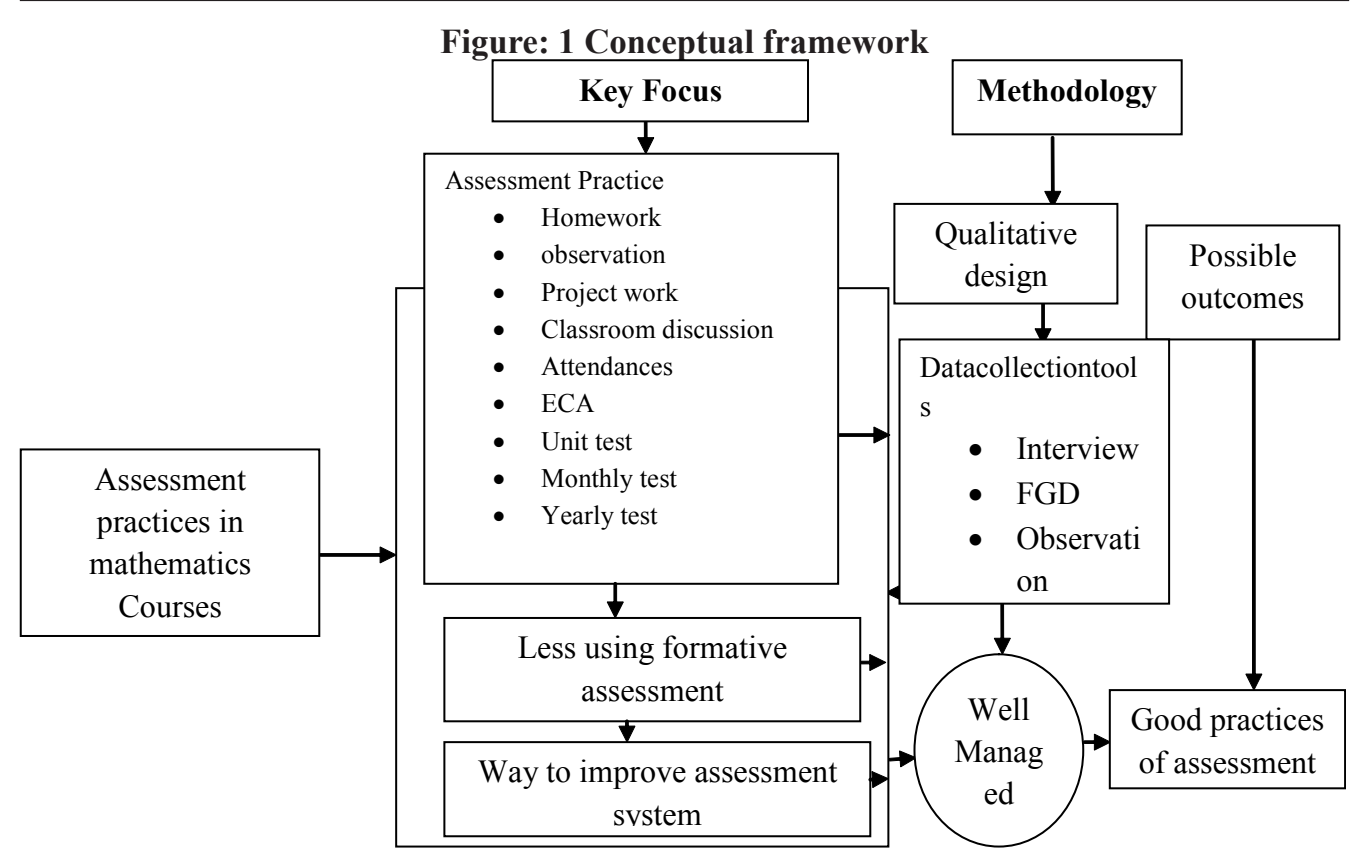

(Sources: NCF, 2007)

\section{Methodology}

Research design is a plan or proposal to conduct research, involves the intersection/interconnection of philosophy, strategies of inquiry, and specific methods (Creswell, 2013). Furthermore, research design in this task is the specific plan that is based on the research problem and research objectives revealing expected finding/data types, and is a road map on how researcher engages throughout the research process. This study has used a qualitative approach to explore student assessment practices at school level in Nepal. The purposive sampling for this study has been used to select the samples. One school from each of the 3 distircts- Gorkha, Nuwakot and Kaski were the study sites of this study. Six students, three teachers' three head teacher, and three resources persons (R.P.) altogether 15 persons were the respondents of this study.

Data were collected from field observation, interview, focus group discussion and photos. Observation was applied for the study of student assessment practice at school level in Nepal, which included existing assessment practices at local level.

Likewise, to collect the necessary data, I conducted two FGD with students and one FGD with teachers from sample school. The data generated from different sources of each study areas have been verified and critically analyzed through triangulation and using different theories.

\section{Existing Assessment Practices in the Mathematics Course}

This section discusses the key findings based on open interviews, observation, and focus interviews with the participants. The ideas that I explored through these data collection strategies have been analyzed under specific themes. The assessment practices have been further analyzed from 
theoretical perspectives in order to make deeper understanding of the participants' perception and practices.

\section{Engaging Students in Classroom through Formative Assessment}

In the classroom, many creative works and activities can be conducted as formative assessment to replace the paper pencil written test. In the past, to enhance students' performance, teachers had focused on written exam as assessment strategies. But only written exams cannot enhance students' creativity and cannot provide the opportunities of fostering creativity, critical thinking, and meaningful engagements. Presentation, classroom discussion, group collaboration, critical writings are the best ways to enhance students' inherent capacities in different mathematical tasks. I understood that the schools have been practicing formative assessment that has changed the way of assessment system . In this system, teachers have many responsibilities to decide the students' performance. In this issue, my teacher participant shares his view as, "After the introduction of formative assessment system, I am not using written test only. I focus on group work presentation, group collaboration and it helps the students to discuss on different issues related to my subject mathematics."

The above information shows that, in formative assessment system, group collaboration, discussion, presentation are being used in the classroom to engage the students. In this regards, Vygotsky (1978) argues that students can learn different tasks of mathematics through active engagement of students. Similarly, multiple intelligence theory focuses on the verity of activities to enhance capacity and creativity of students with multiple intelligences.

\section{Limited Use of Formative Assessment in Classroom Practices}

Since at the end of unit or time of instruction we generally take test to assess what students have learnt. This conception is gradually changing as it is a continuous process. NCTM (1998) an assessment is a broader term defined as a process for obtaining information that is used to make decisions about students, curricular programs and policy. Nowadays the teachers perceive only written test is not proper way of assessing students' learning. According to them assessment of the students can be done by using different tools like students response to question, group discussion, students work, students reflection, group presentation, project work, test and quizzes. In this regards participant from Institution school shares his view as,

Along with several written tests I used unit test, homework, as the means of assessing the students. I think only written test could not represent overall development of child. So we need to practice multiple ways to assess the students' performance but we are unable to apply all types formative assessment practices prescribed in the curriculum like project work. In the same vein one head teacher from community school of Gorkha claims that "however in my school I assess

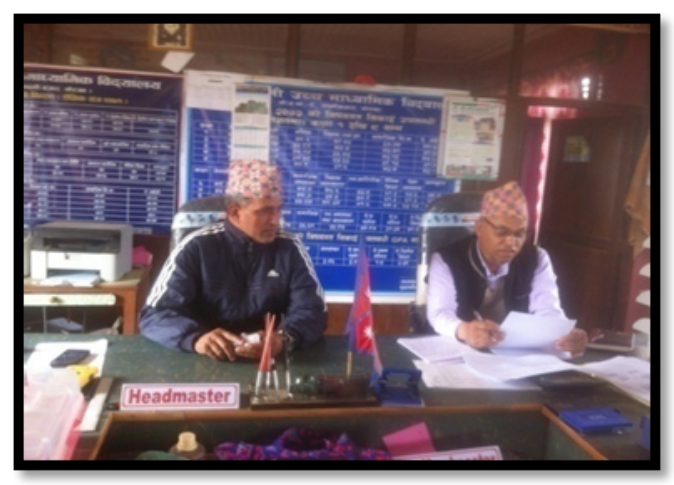


the students through not only home assignment, written test such as weekly test, monthly test, half yearly examination, yearly examination, oral test but also through cumulative records, class work, observation experimentation". Likewise, one teacher from community school said that the assessment practices in the school as,

In my subject mathematics, I have assessed students' performance in the following ways: by assigning, checking and providing feedback of class work, homework, group work and project work. By paper pencil test such as class test, unit test, weekly test, performance test, terminal exam and annual exam.

From the above information I concluded that teachers were familiar with the proper use of tools of assessment of students performance but practically they are not using it properly. Even though head teacher and teachers in their school, practice formative assessment they were unable to implement in the actual assessment process of the students' performance in the school. A teacher of institutional school about the practice of assessment system opines,

In every class from class one to class ten, daily class work and homework checking and providing feedback individually for the improvement of students' learning. In class 8, 9 and 10, weekly exams have been conducted on every Saturday. We take written exam of one subject in a week. Performance test and terminal test are also conducted and have been provided the feedback with mark-sheet. Practical work and group work are also assigned to the students of lower secondary and secondary level. Listening and speaking tests are also conducted for each class from 6 to 10 .

From the above views of a teacher, it was claim that formative assessment has been given less priority.

Similarly, for upgrading the students summative assessment the one of the teacher participant said from the community school shares his view as,

Mainly terminal exam and annual exam have been conducted to upgrade the student. In these exam mainly written tests, oral test, listening and speaking test, project work, practical exam especially in computer science, general science and occupation business and technology education subjects are used to assess the students' performance for the purpose of upgrade.

In the Green Garden Boarding school is one of the institution school situated in Kalikashan, Rusuwa. In my concern about the assessment practices in the school one of the teacher and group of students shares their view as

We should implement the advance and well developed types of system, in the school. At

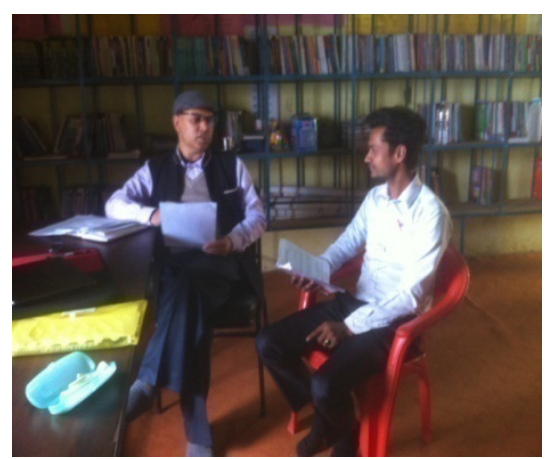


the present age, we can introduce the students' different types of developed equipment, which help to develop the students characters. Such types of practices help to develop the students' mental. There are some assessment practices in my subject mathematics are listed below:

- Project work

- We can teach the students by playing with different materials.

- By using paperwork

- By making teaching aids

- By making different objects with the help of Chinese clay

- Unit test

- Monthly test

- Class work

- Homework

- By telling different stories

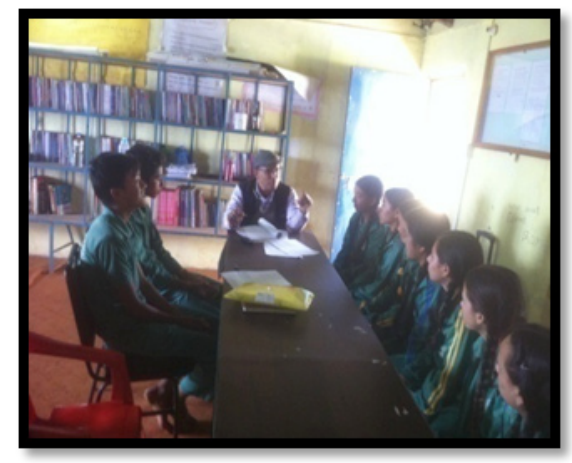

From the above information it was concluded that there is used various tools of assessment practices to assessing the students performance. So definitely the learning capacity of the students should be improved

\section{Use of Summative Evaluation as a Formative Assessment Tool}

To obtain the view of students about the practices of assessment system we carried out the FGD among 10 students in Shree Mahalaxmi Secondary School Gorkha. From the FGD, I found that students were positive about the assessment practices of the school. Teachers were more helpful. Every Saturday they take the exam. They call it Sanibare exam. So that we have good practice of exam. We enjoy in the class work and homework. Teachers take regular attendance. In our school, CCTV are used. Through this CCTV teachers and head teacher observed our activities from the office. So all we engage in our classwork, discussion the subject matter with friends as well which foster

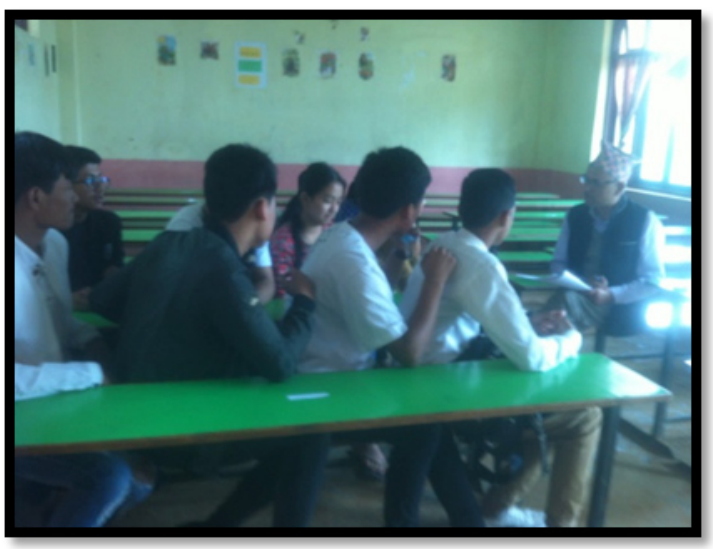
learning.

\section{Gradual use of Formative Assessment System in School}

In this regard, teachers have different view of formative assessment practices. According to them" theoretically formative assessment system is not bad but it is less implemented properly. In the case of Gorkha district, these types of practices are less successful". From the FGD of 
teachers claimed that, in one hand formative assessment system can be implemented gradually. Some lapses are there in examination board and other consultants. So, in the case of Gorkha district, there is gradualformative assessment practice in mathematics course.

\section{Ways to Improve the Formative Assessment System}

For improving the assessment the following themes were generated:

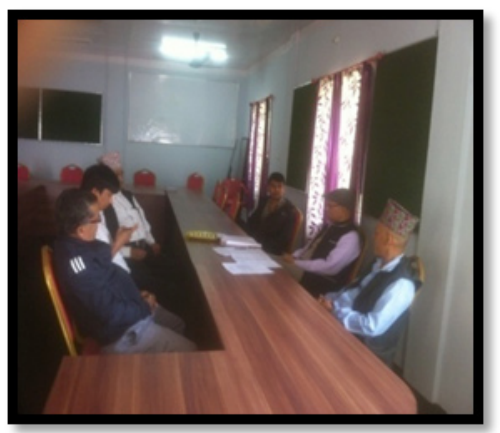

\section{Through Implementing Culture Friendly Assessment}

Culture refers to the shared norms and values established by the society to fulfill the needs and goals of contemporary society. It is the set of activities to be performed to produce meanings. Cultural practice is a source of knowledge. When we evaluate the students' performance, we have to link our assessment system with students' culture. Then, only our assessment system becomes culture friendly. When asked how do they assess students from cultural perspective ateacher from Gorkha shared that

Until now we have only tools of evaluating i.e. the written test. This system of evaluating has become out dated and unscientific at the modern time. Students can be given project work, group interaction, individual and group presentation, written reflections. They should be encouraged to participate in different cultural work, continuous evaluation. Then it becomes culture friendly. In this issue my other participant from Gorkha opines that there are several techniques such as oral questioning and written tasks of assessing the students who are culturally different from paper pencil test such as project work, case study, group work.

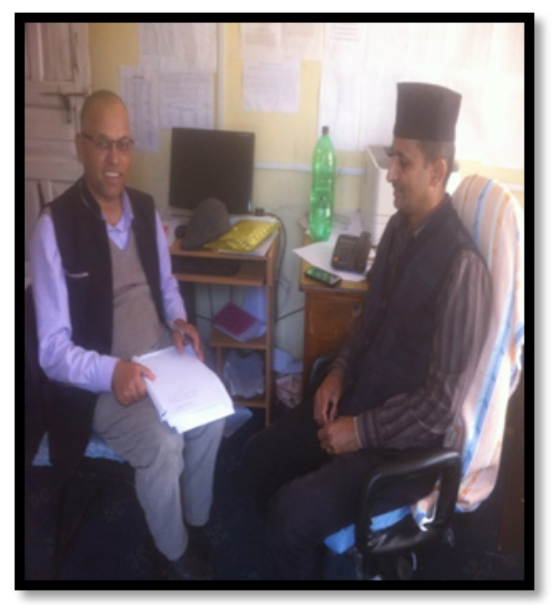

The above text gives the message that the paper pencil based students' assessment system has become less effective. Therefore, for making the system effective and culture friendly, it needs to adopt multiple ways of assessment to link student culture such as project work, group work, paperwork, class participation, homework. NCTM Assessment Standards (1995) defines "an assessment is a broad term defined as a process for obtaining information that is used to make decisions about students, curricular programs, and policy". The use of proper authentic assessment practice gives option of improving the student' learning. Then, only the indigenous ways of gaining competencies, and respecting the identity of cultural groups in evaluating the students learning performance can be seen. Berger, Giroux, and Lariviere (2002) states that many writers on learning assessment have confirmed that paper pencil tests are inadequate because they don't readily reveal the student's thinking. In my opinion, although, tests are the part of assessment, test are normally given at specified time intervals. Thus, for finding out overall progress of a student, 
a test would not provide complete information. So, it would be better to implement continuous assessment system to evaluate the students overall performance.

From the view of Head of Education Department of Pokhara Lekhnath Metropolitan city, Pokhara shared that the improvement of formative assessment system is possible through providing all responsibilities of the teachers.

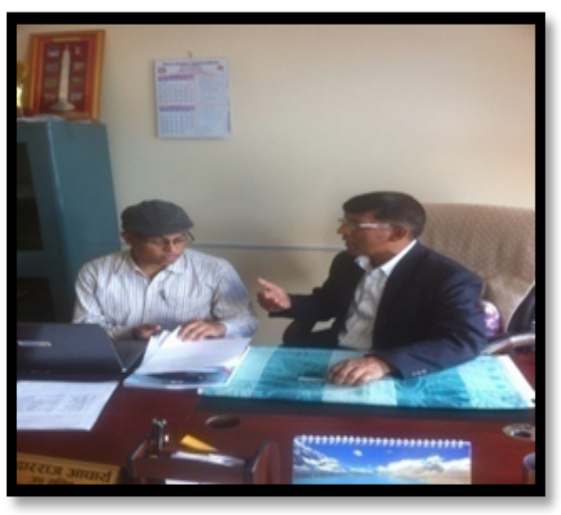

\section{Incorporating Local Knowledge in Students Assessment}

In general, conception of assessment is limited to evaluate individual performance by taking tests at the end of unit or time of instruction, what the students has already learned. The term assessment is used in the sense of judging the extent of students learning (Freeman \& Lewis, 2005). Assessment is a major contributor to raising standard in school in terms of teaching, learning and achievement (Cohen, Monion \& Morrison, 2008). The main goal of classroom testing and assessment is to obtain valid, reliable and useful information concerning students' achievement (Linn \& Miller, 2008). This process of assessment is slowly changing as it is continuous process.

Assessment of students can be done through various ways: by observing their facial expressions and observing their activities, by looking at their written work, by asking questions and listening to their ideas, by supporting discussions, and by providing just enough supports for students to progress (Tanner \& Jones, 2008). Assessment of teaching learning activities is essential at the end of the lesson and it is necessary to assess the extent whether learners understand or not the key issues.

On observing teaching activities of teachers, I found that they used their own methods for assessment for learning. Some of the teachers did not use assessment for learning in the class, some left the baseline assessment, some end assessment and most of them left the assessment of their main teaching. In this issue of assessment a teacher said:

The existing assessment system focuses on the paper pencil test which might not be scientific in many senses. So the provision of continuous assessment system should be incorporated in the curriculum and recognized as an integral part of the teaching learning process.

Likewise, other participant put forward their views as assessment is not a separate thing from instructional process. It should go hand in hand. If there is only teaching, you do not know where you and your students are, and only assessment does not make students learn. For this, teaching and assessment should be complementary to one another and assessment must be ongoing. 
Therefore, present practice of assessments in the school level fails to address the interest and needs of diverse background of the students. To measure the students' all round capacity we apply other device of evaluation such as assigned project work, home assignment, group work and continuous evaluation of the students. Such evaluation enables teachers to evaluate the students' multiple intelligence, ultimately resulting in exploring their inherent capability for learning. Then, they enjoy learning and the teacher can treat them according to their interest and needs.

\section{Avoiding Rote Memorization while Practicing the Assessment}

Rote memorization is still popular in Nepalese classroom. The Western classrooms have turned away from this method of learning. This changing approach has much to do with cultural beliefs regarding how students learn best and what each culture values in its students. In our concern for improving formative assessment practices in applying the school of Nepal, my respondent Head of Examination section in Gorkha expressed his view as,

Only the rote learning without understanding the subject matter, destroyed the students critical thinking. It kills the creativity of the learners. So the primary concern of the teacher is to enhance the creativity and make students to enjoy the subject matter. Teachers are now incorporating more problem-solving and investigation activities to replace the traditional skill and drill exercises that were previously used in our schools then ultimately our assessment system gradually improve.

From the above view of my participant, it was found that without understanding the subject matter, the only rote memorization is meaningless to learn. Therefore, the primary concern of the teacher is for the student to acquire the content through understanding the subject matter through assessment.

\section{Follow the Multiple Ways to Assess the Students' Performance}

There are many ways to assess the students' performance in school. Only single way to evaluate the students' performance is not sufficient. In this regard, teacher participant from Rusuwa shares his view as

In addition to different written test we have to use project work, class participation, class activities, home assignment, group discussion and portfolio. So, to improve our formative assessment practices we need to apply the multiple ways to assess the students' performance better.

From the above saying it was claimed that using multiple ways to access the students' performance is the best way only paper- pencil tests are not adequate. To assess the students' performance we apply multiple ways then the performance of students gradually increasing.

\section{Providing the Appropriate Teachers' Training for Assessing the Students Performance}

Teacher's professional development carries two important aspects, namely -teacher development and professional development. Equipping teachers with relevant knowledge and the methods of effective delivery and suitable assessment of the students' performance. As teacher is one of the 
main doors in teaching learning activities and evaluation process. Teacher education involves educationist, managers, experts and teacher students. As the teachers are important instrumental for the implementation of the curriculum, their roles become the most important in teacher development process. The teachers are considered as an ideal person for the purpose of educating students. In this issue my informant head teacher from community school shares his view as

High qualification is itself a development of teacher, but still they need the techniques and skill of effective delivery and evaluate the achievements of the contents which is not possible without proper training. Teachers should be given trainings about proper teaching and assessing the students' performance then only they should enter the class. Knowing a lot of in any subject does not make an effective and successful teacher unless she/he takes care of lecture delivery in proper curricula. We take many trainings but the training did not focus on the assessment of the students. So, it is better to conduct the training particularly focusing the students performing in classroom learning.

From the above information it was concluded that only training is not sufficient for the students' performance. Rather the training should focus in the particular area which our need meets. So, training should focus on how to assess the students' learning in diverse classroom.

\section{Fully Applying Continuous Assessment System to Assess the Students Learning}

Continuous assessment system helps in developing student's logical and creative thinking abilities. Students work in group and individually, explore and investigation of the subject matters and they construct, compare and justify the concept. Only the period of implementing continuous assessment, all the above method activities were performed well. It helps them to communicate their thinking in obtaining the knowledge while using continuous evaluation. In this issue my informant resour person of Gorkha shares his view as

In the continuous assessment system teachers and students are engaged in their work. The students deeply enjoyed and found more interested to learn different concepts by using different methods such as daily and weekly observation, extra activities, project work, home work working with group, presentation and interacting with student and teacher. Also developed the behavior of student's such as; carrying out the assignment, helping others, participation in class activities and creativity.

Above interview shows that CAS is very effective than traditional student's assessment system. For this students should be given project work and home work regularly in school. The head teacher should be encouraging teachers to use CAS. Sufficient financial support from government should be given for CAS implementation to schools. Ministry of Government and District Education Office should play the facilities role and provide exports and organize many teachers professional development training programs for the teacher to increase the efficiency of them, for improving the assessment system different stakeholder did the responsibility. 


\section{Commitment About Implement of Formative Assessment}

School administrator and teacher team should commitment about implementation of continuous assessment system up to grade seven and grading system in every class. Every teacher should motive to assess student innovative ways such as project work, group work, presentation and demonstrations etc. in this line the teacher share his view as,

Resource person should regularly monitor the school activities, classroom teaching and evaluation process. He also should provide suggestions and feedbacks after monitoring and observation.Local agency should frequently monitor the school activities and provide appropriate feedback and suggestions. The school inspectors and other officers from related agencies should regularly monitor the school and should negotiate with teachers, students and parents and they should provide feedbacks and suggestions for further improvement.

Above interview show that CAS is very effective than traditional student's evaluation system. But it is important to encourage students for active participation and enough time should be given at home to do class work, project work and home work regular in school. It is also important to provide training to the teachers for their professional development. The head master should be encouraging teachers to use CAS. Sufficient financial support from government should be given for CAS implementation to schools. Ministry of Government and District Education Office should play the facilities role and provide exports and organize many teacher professional development training programs for the teacher to increase the efficiency of them.

\section{Follow the Comprehensive Assessment System/ Policy}

Comprehensive assessment policy has been developed with the purpose of addressing assessment related concerns that have emerged in recent years. If this policy is applied it would be helpful for nation as whole. This is the technique to increase manpower and the policy of doing right evaluation. But there is a doubt about the continuous process. In this regards academic principle from constitutional school shares his view as,

A comprehensive assessment policy has been developed with the purpose of addressing assessment related concerns that have emerged in recent years. If it is really implemented it helps to make for the manpower and become real evaluation in a nation but it is doubt in implementation part. Furthermore we can say that comprehensive assessment has not been focused in our practices. For example we can get multiple information from a single question through the comprehensive assessment.

From the above mentioned data it is cleared that comprehensive assessment system evaluate the students differently. A comprehensive assessment system as comprising a range of measurement approaches used to provide a variety of evidence to support education decision-making. In such a system, multiple measures enhance the validity of inferences drawn from assessment. Formative assessment is a process used by teachers and students during instruction that provides feedback to adjust ongoing teaching and learning to improve students' achievement of intended instructional outcomes. In this regards, Levinson (2000) argues Germany, Israel and Japan with the aim to 
find as many different kinds of assessment and educational systems as possible from as many continents as possible. He conducted that different countries vary in multiple ways to assess the students performance. He mention that Brazil, England and Japan, conduct national-level tests, but each country does so for different reasons: Brazil for state-by-state comparisons and program evaluation, England for school accountability and Japan for college entry. To maintain this comprehensive assessment system is essential for quality education.

\section{Findings}

Existing Assessment Practices in the Mathematics Course

From the above analysis and interpretations the existing assessment practices implemented in the Nepalese classrooms by the mathematics teachers were as,

- Engaging students in classroom through formative assessment

- Limited use of formative assessment in classroom practices such as project work, class work, and homework, project work (less), attendance, unit test, remedial support, extracurricular activities, field visit, and group discussion, weekly tested.

- Use of summative evaluation as a formative assessment tool

- Gradual use of formative assessment system in school

\section{Ways to Improve the Formative Assessment System}

In regard to improve assessment system, we have visualized the following themes

- Through implementing culture friendly assessment

- Incorporating local knowledge in students' assessment

- Avoiding rote memorization while practicing the assessment

- Follow the multiple ways to assess the students' performance

- Providing the appropriate teachers' training for assessing the students' performance

- Fully applying continuous assessment system to assess the students learning

- Effective monitoring system

- Providing appropriate reference materials

- Strong political commitment to make school academic environment

\section{Conclusions}

Theoretically teachers were aware on formative assessment system but practically they were less implementing formative assessment practices. The practices were under gradual improvement. Assessing learning alone is not sufficient because the ultimate success of students is also depend upon their motivation and commitment to learning. So, teachers should be encouraged to follow the formative assessment system for students' better performance. From the above findings it is concluded that teachers implement both types of practices formative and summative assessment process is going to dialectical ways. It is better if we should be providing the appropriate teachers' training for assessing the students' overall performance, fully applying continuous assessment system to assess the students learning, effective monitoring system, providing appropriate 
references material, and strong political commitment to make academic environment in the school then our assessment practices become students and teachers friendly, ultimately quality of education will gradually improve.

\section{References}

Airasion, P. W. (1999). Classroom assessment. available on: www.eric.edu.gov.

Altan, A. (2002).Assessment for multiple interagency, valuable on www.eric.edu.gov.

Cohen, L., Manion, L, and Marison (2006). Research methods in education. Newyork: Routledge Falmer.

Cresswell, J. W. (2013). Research designing: qualitative, quantitative and mixed methods approach. London: Sage.

Ghaicha, A. (2016). The theoretical framework for educational assessment: A synoptic review. Journal of Education and Practice, 7(24), 212-226.

Levinson, C. Y. (2000). Student assessment in eight countries. Educational Leadership, 57(5), 58-61.

National Council of Teachers of Mathematics (1989). Curriculum and evaluation standards for school mathematics, Reston, VA.

NCF, (2007).The national curriculum framework for school education in Nepal. Ministry of Education, Kathmandu.

Tu, R. (2009). Assessment of mathematics education in China. Journal of Mathematics Education, 2(1), 115-120.

Vandeyar, S., \& Killen, R. (2007).Educators' conceptions and practice of classroom assessment in post-apartheid South Africa. South African Journal of Education, 27(1), 101-115.

Vygotsky, L. S. (1978). Mind in society: the development of higher psychological processes. M. Cole, V. John - Steiner, S. Scribner \& E. Souberman (Eds.), Cambridge, MA : Harvard University Press. 